\title{
Concentrations, spatial distribution, and human health risk assessment of asbestos fibers in ambient air of Tehran, Iran
}

\author{
Majid Kermani $^{1,2} \cdot$ Ahmad Jonidi Jafari $^{1,2} \cdot$ Mitra Gholami $^{1,2} \cdot$ Farhad Taghizadeh $^{1,2} \cdot$ Hossein Arfaeinia $^{3,4}$. \\ Yousef Abdolsalami ${ }^{5} \cdot$ Abbas Shahsavani $^{6,7}$
}

Received: 20 September 2020 / Accepted: 23 April 2021 / Published online: 1 September 2021

(C) Saudi Society for Geosciences 2021

\begin{abstract}
The aim of current research was to determine airborne asbestos fiber concentrations in the ambient air of Tehran, and to investigate their spatial distribution, seasonal variation, and human health risk assessment. For this, the sampling of the study was carried out during August 2017 and June 2018, and totally, 64 samples were taken from 8 stations along the different areas of Tehran. The concentrations of airborne asbestos fibers were determined by phase contrast microscope (PCM) and scanning electron microscopy (SEM) analyses. Spatial mapping was conducted using the inverse distance weighting (IDW) technique. The health risk assessment was done based on the detected levels of airborne asbestosis fibers. The mean concentrations of the airborne asbestos fiber were $1.9 \times 10^{-3} \mathrm{f} / \mathrm{ml}$ and $595 \times 10^{-3} \mathrm{f} / \mathrm{ml}$ based on PCM and SEM analyses, respectively. One of the effective factors on ambient level of asbestos fibers is meteorological parameters, where the maximum and minimum concentrations of asbestos fibers are related to cold and warm seasons, respectively. These differences could be due to the presence of inversions phenomenon in cold seasons in Tehran. It was observed that the excess lifetime cancer risk (ELCR) calculated for all the sampling areas are between $5.26 \times 10^{-5}$ and $5.37 \times 10^{-4}$. Based on the EPA-suggested standards $\left(10^{-4}-10^{-6}\right)$, these values are categorized rather to moderate levels. The obtained data indicated no threat of asbestos fibers to Tehran's citizens' health.
\end{abstract}

Keywords Air pollution · Asbestos fibers $\cdot$ Risk assessment $\cdot$ Tehran $\cdot$ Responsible Editor: Amjad Kallel

\section{Introduction}

Asbestos refers to a group of silicate minerals classified into amphiboles ( including amosite, crocidolite, termolite, actinolite, and anthophyllite) and serpentine which is asbestos of chrysotile type (Kakooei et al. 2009). Amphiboles are hazardous for human health due to their carcinogenic properties

\footnotetext{
Responsible Editor: Amjad Kallel

Farhad Taghizadeh

f.taghizadeh21@yahoo.com

Hossein Arfaeinia

Arfaeiniah@bpums.ac.ir

1 Research Center for Environmental Health Technology, Iran University of Medical Sciences, Tehran, Iran

2 Department of Environmental Health Engineering, School of Public Health, Iran University of Medical Sciences, Tehran, Iran

3 Department of Environmental Health Engineering, School of Public Health, Bushehr University of Medical Sciences, Bushehr, Iran
}

(Khadem et al. 2018). Use of asbestos over the recent decades has become very common because of its unique characteristic properties (being inexpensive, desirable quality, resistance to heat and chemicals, strength, flexibility, and low electrical conductivity) (Walton 1982). These properties have led to its application in synthesis of different products such as cement asbestos pipes, brake pads and clutch, roofing sheets, building

4 Systems Environmental Health and Energy Research Center, The Persian Gulf Biomedical Sciences Research Institute, Bushehr University of Medical Sciences, Bushehr, Iran

5 Department of Occupational and Environmental Health Deputy of Health, Iran University of Medical Science, Tehran, Iran

6 Air Quality and Climate Change Research Center, Shahid Beheshti University of Medical Sciences, Tehran, Iran

7 Department of Environmental Health Engineering, School of Public Health and Safety, Shahid Beheshti University of Medical Sciences, Tehran, Iran 
pipes, façade panels, floor tiles, building insulators, glue, flooring, and ventilation canals. Asbestos is also utilized in industries as a strength agent as well as durability and for prevention from abrasion and combustion (Pawełczyk and Božek 2015; Napolitano et al. 2016). In general, any structure which has asbestos textures can emit the asbestos fiber to the ambient air. These activities include construction and deconstruction of buildings as well as transportation processes. One of the main sources of asbestos in the atmosphere of cities is the clutch and brake inside automobiles (Mokhtari et al. 2019), where the most common type of asbestos fibers used in clutch planes by $30-60 \%$ is crocidolite fibers (Lim et al. 2004; Jiang et al. 2008). Both light and heavy vehicles emit considerable amount of asbestos fiber into the air due to the friction and abrasion between brake pad and disk of sheets (Lim et al. 2004), such that according to the report by American Environmental Protection Agency, 32 million kg of asbestos is emitted into the air due to abrasion of brake pads every year (Kakooei and Marioryad 2010). When asbestos fibers are emitted to the air, they could travel far distances due to their aerodynamic properties, and since no chemical degradation occurs in the fibers, thus the only way for their elimination from the atmosphere is precipitation (snow and rainfall) (Commins 1985). Since asbestos is not volatile, they are also emitted into the open air as small fibers and patches of asbestos in the form of dust (Falgout 1985), developing various health effects for humans.

Humans may be exposed to different kinds of asbestos in the air, but generally fibers less than 3 microns in diameter can penetrate deep into the respiratory system, and thus have a greater pathogenicity potential (Pastuszka 2009). Evidences of asbestos pathogenicity and its function in the development of lung cancer and mesothelioma have grown since the mid1960s (Sullivan and Krieger 2001). When air polluted with asbestos fibers is inhaled, these fibers get stuck within the lungs and can reside there for a long time, causing serious diseases such as asbestosis, lung cancer, mesothelioma, and other pulmonary issues (including pleural plaques, thickening of the membrane around the lungs, pulmonary secretions) (Kakooei and Normohammadi 2014). Although all forms of asbestos are carcinogenic, due to their special physical characteristics, the fibers of crocidolite type can penetrate deep into the lungs and transfer to the lung tissues. Because of this, they can be claimed as the most hazardous type of asbestos fiber (Kakooei and Marioryad 2010). Moreover, the amosite and termolite asbestos types have also greater toxicity compared to chrysotiles due to their smooth and small fibers, and indeed all three types of fiber have a high pathogenicity potential especially in developing mesothelioma disease (Moteallemi et al. 2020). Currently, asbestos categorized as Group A1 or human carcinogenic (Cancer 1977), and according to the annual report of Cancer Research Institute, in 2005, 55 cases of asbestos-associated mesothelioma were reported in Iran (Naghavi 2005). As a result, asbestos fiber is now one of the most widespread and significant groups of hazardous air contaminants, attracting the attention of many researchers due to its occurrence, fate, and possible ecological risks.

Tehran is the largest city of Iran and one of the most populated cities of the Middle East and even the world (Fig. 1), in which various industries including refineries, furnaces, chemical-producing factories, and extraction and melting of metals are established. Furthermore, the presence of vehicles beyond the capacity and the geographical location and natural factors such as mountains in the north and east of this city have intensified the air pollution in this city. As above-mentioned, asbestoses are a group of important air pollutants in cities, which have a great potential in developing health problems. Thus, monitoring and evaluating the concentration and toxicity of these compounds in the air of cities are crucial. Sporadic studies have been done on asbestos fiber in the air. However, they have focused only on the levels of this fiber in the ambient air of industrial areas (Kakooei et al. 2007; Kakooei and Marioryad 2010), and so far no evidence has become available about assessment of health effects of the asbestos fiber in the ambient air for public exposure. To the best of our knowledge, the present research is a unique study in this regard, which can fill this scientific gap. Therefore, the current research was designed with the following goals: (1) determining the concentration levels and spatial distribution of asbestos fiber in Tehran's ambient air, (2) determining seasonal variations of asbestos fiber levels in Tehran's ambient air and its relationship with meteorological parameters, and (3) evaluating the health effects for the public in Tehran who are exposed to and inhale asbestos fiber-containing air. The results obtained from this research can provide useful information on distribution of asbestos fiber in the Tehran ambient air and its adverse effects on the public health for policy makers and managers in Tehran, so they will be able to devise better policies and programs to control and even prevent entrance of these pollutant compounds to the Tehran's ambient air.

\section{Materials and methods}

\section{The studies site and sampling}

The present study was designed and conducted in Tehran City (longitude and latitude of $35.6892^{\circ} \mathrm{N}$ and $51.3890^{\circ} \mathrm{E}$ ), capital of Iran and the most populated city in the Middle East (Bayat et al. 2019). For this purpose, 8 stations were selected from different areas of Tehran and the sampling was carried out from the ambient air between August 2017 and June 2018. Figure 1 demonstrates Tehran's map, which depicts the sites chosen for taking samples from the aerial asbestos. The points selected for sampling were considered in residential, industrial, and traffic-laden areas of the city. Furthermore, to 


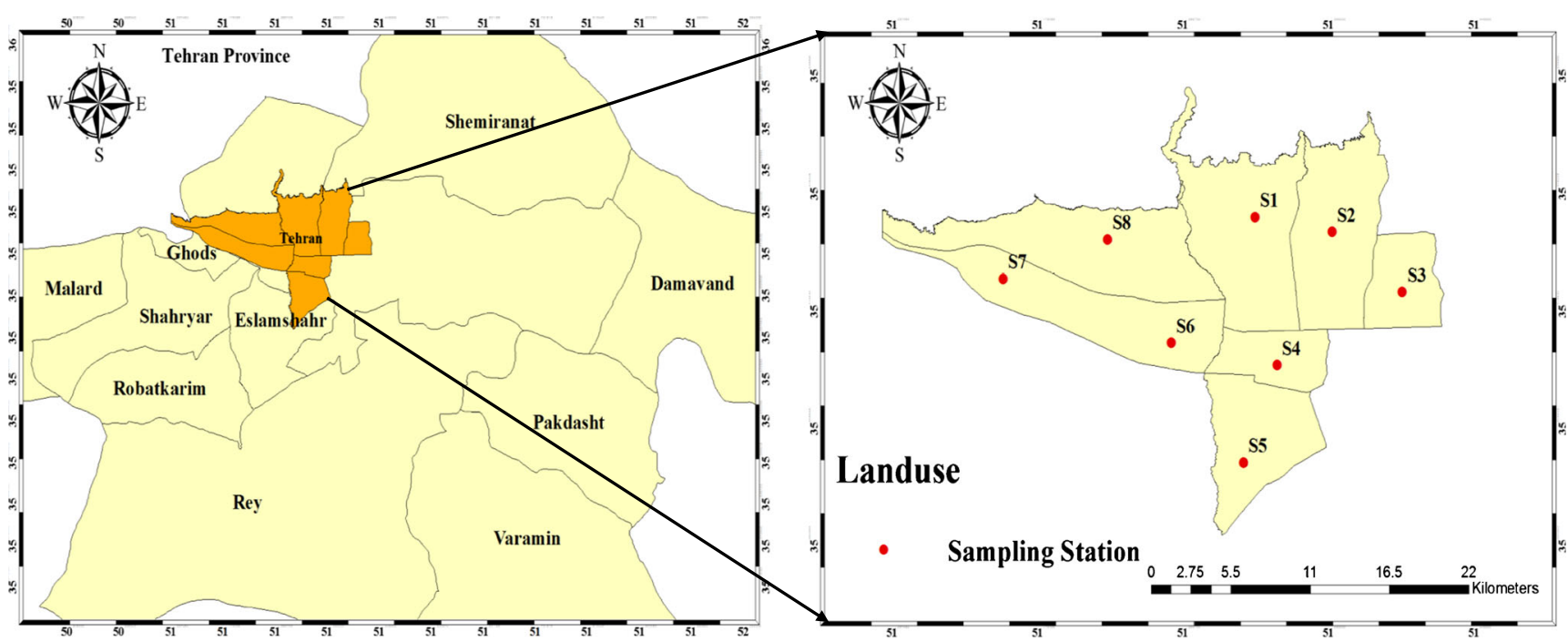

Fig. 1 Location of study area and sampling stations

investigate the trend of seasonal variations of asbestos concentrations in Tehran's air, the sampling was done in four different seasons of the year with 45-day frequency. A total of 64 samples were collected from all study locations, and the level of asbestos in them was determined. To perform the sampling, a high volume system was used to collect the fibers on mixed celluse ester (MCE) with a pore size of 0.45 micron and diameter of $25 \mathrm{~mm}$ (SKC) as well as a cassette holder (Model, Zefon, Z008BA). A cassette holder was used to neutralize the effects of static electricity and increase the fiber precipitation efficiency on the filter. The samplings were carried out for $8 \mathrm{~h}$ using a peripheral pump (Leland legacy, SKC, USA) with a flow rate of $61 / \mathrm{min}$. The equipment for sampling the ambient air was placed $3 \mathrm{~m}$ above the ground level. Note that before the sampling process, all pieces of equipment used to include the pumps, etc. were calibrated. The mean temperature, relative humidity, and wind speed were $36{ }^{\circ} \mathrm{C}, 7 \%$, and $11 \mathrm{miles} / \mathrm{h}$, respectively, during the sampling. Also, in order to reduce the sampling error, the filters related to each station were investigated for the presence of fibers by phase contrast microscope (PCM) before sampling.

\section{Preparation and analysis of the samples}

After the sampling, the samples were transferred to the laboratory for analysis, and the samples' analysis was done by phase contrast microscope (PCM) method. The scanning electron microscopy (SEM) method was then used to validate the findings. For measurement by PCM method, the sampled filters were prepared according to NIOSH 7400 guideline and analyzed, such that first the filters were divided into two equal parts and then one part of it was cleared by an acetone flash vaporization system. After this step, the cleared filters were transferred onto a slide under phase contrast illumination (Walton-Bechette graticule (type G-22)) electron microscope, whereby the fibers were counted with a magnification of $x$ 400-450. Then, according to Eqs. (1) and (2), the level of fibers was observed in terms of fiber in air milliliter in PCM method. Note that fiber was defined as fiber particles with a length of over $5 \mathrm{mcm}$ and length-to-diameter ratio of 1:3. The detection limit of the PCM method was around 0.01 fiber $/ \mathrm{ml}$. Fiber counting was done according to EC/18/2003 rules of European Parliament and Council 27 March 2003 in protecting workers from the hazards related with exposure to asbestos in the workplace. The counting rules also corresponded to the requirements of ISO Standard 14966 and German VDI standard 3492.

$E=\frac{\frac{F}{n f}-\frac{B}{n b}}{\text { Af }}$ fiber $/ \mathrm{mm}^{2}$
$C=\frac{A c \times E}{V \times 1000} \quad$ fiber $/ \mathrm{cc}$

E the fiber density of the filter surface

$E /$ the number of fibers counted in each graticule field in

nf the sampled filter

$B /$ the number of fibers counted in each graticule field in

$\mathrm{nb}$ the control filter

Af graticule field $\left(\mathrm{mm}^{2}\right)$

$C \quad$ fiber concentration ( $\mathrm{f} / \mathrm{ml})$

Ac the useful surface area of the filter $\left(\mathrm{mm}^{2}\right)$

Although PCM method is relatively fast and inexpensive, it has the drawback of being unable to distinguish between asbestos and non-asbestos fibers. It cannot detect 
fibers thinner than $0.25 \mathrm{mcm}$ either. To address these issues, the second half of the filters was prepared and was evaluated by scanning electron microscopy (SEM) combined with energy-dispersive X-ray analysis (EDXA). In this technique, the samples were studied after being coated with a thin layer of gold (some nanometer) under vacuum conditions by SEM with a magnification of 2000. To determine the chemical composition of the observed fiber, EDXA analysis was conducted. Based on the results obtained from this method, the asbestos fiber percentage out of the non-asbestos percentage present in the samples is measured along with the percentage of different asbestos types. Note that the detection limit of SEM method is around 0.0001 fiber $/ \mathrm{ml}$. SEM method can detect both smaller fiber and type of fiber, but its accuracy in fiber counting is not very good due to the sample region which can be scanned at high magnifications (it does not have a good accuracy). Then, for quality control, alongside the main samples, blank, reference, and control samples were also prepared and analyzed.

Finally, the asbestos fiber concentration was calculated based on SEM method and using Eq. (3).

$C=100 N \pi r 2 / V \times n \times a \mathrm{f} / \mathrm{ml}$

$C$ the number of asbestos fibers per each $\mathrm{ml}$ of air $(\mathrm{f} / \mathrm{ml})$

$N$ the number of observed fibers

$r$ filter radius (mm)

$V \quad$ the volume of the samples air (1)

$n \quad$ Number of counted fields of images

a Calibrated area of each image $\left(\mathrm{mm}^{2}\right)$

\section{The spatial distribution of asbestos in Tehran air}

ArcGIS 10.5 software developed by Environmental Systems Research Institute (ESRI) Corporation was employed to investigate the spatial distribution of asbestos fiber in Tehran's air. For this purpose, interpolation technique of inverse distance weighting (IDW) type was used to develop independent raster layer for the mean annual concentration of asbestos fiber and determining their distribution. Then, calculator raster function was utilized for overlaying each layer and generating the seasonal mean maps of the asbestos levels. IDW method has been used so far in different environmental researches for mapping the distribution of environmental pollutants including particulate matters, ozone, polycyclic aromatic hydrocarbon (PAHs), and polychlorinated biphenyl (PCBs) (Faridi et al. 2019; Abbasi et al. 2020). It is indeed a nonstatistical method which is typically used for predicting the pollutants' level in unmeasured points through optimal special prediction technique. This technique is very useful when the distribution of estimated parameters is abnormal. The IDW model assumes that the predictions are in a linear function of the available data. Formula 4 shows the IDW model.

$i=\frac{D i-\alpha}{\sum_{i=1}^{n} D i-\alpha} \quad$ (no unit)

In this formula, ${ }_{i}$ represents the weight of each sampling point, $D i$ denotes the distance between the sampling point $i$ and an unknown point, $\alpha$ is the weighting power, and $n$ shows the number of certain points for interpolation. In this model, higher weighting powers are allocated to closer interpolated points, and for farther points, the weighting power diminishes.

\section{Assessing health effects}

According to United States Environmental Protection Agency Integrated Risk Information System (USEPA IRIS) references, asbestos risk assessment is done based on the values observed by PCM method (EPA 1986). To evaluate the human health effects, the excess lifetime cancer risk (ELCR) resulting from inhaling asbestos fiber was assessed in Tehran's ambient air. For this purpose, ELCR was obtained by multiplying exposure concentration (EC) by unit factor (URF) (Eq. 5). Indeed, this factor determines the extent of incidence of cancer given the level of asbestos a person has been exposed to throughout their life span. EC was also calculated by Eqs. 5 and 6 (Pawełczyk and Božek 2015):

$$
\begin{aligned}
& \mathrm{EC}=\mathrm{Ca} \times \mathrm{ET} \times \mathrm{EF} \times \mathrm{ED} / \mathrm{AT} \quad(\mathrm{f} / \mathrm{cm} 3) \\
& \mathrm{ELCR}=\mathrm{EC} \times \mathrm{URF} \quad(\text { not unit })
\end{aligned}
$$

In these formulas,

EC : chronic exposure concentration (averaged over a 70year lifetime) $\left(\mathrm{f} / \mathrm{cm}^{3}\right)$, URF : unit risk factor for asbestos inhalation $\left(\left(\mathrm{f} / \mathrm{cm}^{3}\right)^{-1}\right), \mathrm{Ca}$ : asbestos concentration in fibers per cubic centimeter $\left(\mathrm{f} / \mathrm{cm}^{3}\right)$, ET: exposure time in hours/day (it is $24 \mathrm{~h}$ a day in the case of the residents' scenario), $\mathrm{EF}=$ exposure frequency in days/year (in the resident scenario, it is 365 days a year), $\mathrm{ED}=$ exposure duration in years (the value of $\mathrm{ED}$ depends on the age group), and AT = averaging time.

For the risk assessment by this method, URF value was considered 0.23 .

There are also some other methods for asbestos risk assessment, including lifetime average daily dose (LADD) and cancer slope factor (CSF), whose results can be said to the same as ELCR results. 


\section{Statistical analysis}

To perform the statistical analyses, R 3.5.0 software and Microsoft Excel 2013 (v15.0) were used. To evaluate data normality, the Shapiro-Wilk test was utilized. To examine the correlation between the variables of asbestos fiber level, air temperature, and humidity, given the normal data distribution, the Spearman correlation coefficient method was used.

\section{Results}

\section{Distribution of asbestos fiber concentration in Tehran's air}

Table 1 shows the results of PCM and SEM analyses used to assess the asbestos fiber concentration in the air of sampled points in Tehran. Note that the values reported in Table 1 include the total fiber level of asbestos. As seen, the annual mean concentration of asbestos fiber in Tehran's air has been $(0.0019 \mathrm{f} / \mathrm{ml} \mathrm{PCM} \mathrm{-}$ $0.00595 \mathrm{f} / \mathrm{ml} \mathrm{SEM}$ ), which is higher than the guideline value determined for life-span exposure ( 0.0022 fiber $/ \mathrm{ml} \mathrm{SEM}$ ) (WHO 2000a, b). As a result, exposure to Tehran's ambient air should be limited in order to protect Tehranians' health (Pawełczyk and Božek 2015). According to Table $1, \mathrm{~S} 2$ point $(\mathrm{PCM}=0.0029 \mathrm{f} /$ $\mathrm{ml}$ and SEM $-0.0168 \mathrm{f} / \mathrm{ml})$ followed by S8 (0.0148 f/ml SEM $0.0025 \mathrm{f} / \mathrm{ml} \mathrm{PCM}$ ) has had the maximum asbestos fiber level, while the minimum concentration belonged to S1 (PCM: 0.001 $\mathrm{f} / \mathrm{ml}$, SEM: $0.00101 \mathrm{f} / \mathrm{ml}$ ). Generally, the pollutant emitting sources in Tehran air are categorized into mobile sources (traffic) and stationary sources (industrial, commercial, and residential). As vehicles are responsible for more than $70 \%$ of Tehran's air pollution (Faridi et al. 2019), our results also strongly suggested that the high level of asbestos in Tehran's air is mostly attributed to brake, fork, glue, and washer of vehicles. In addition, in some cases, the asbestos fiber has an industrial source, and construction operations can also have a small share in the level of the ambient air asbestos.
In this study, also since S2 point was located in a high traffic area in Tehran, the high level of asbestos in Station $\mathrm{S} 2$ can be attributed to huge traffic load and the large volume of vehicles' commuting in this point (Khadem et al. 2018). Although S8 point is a station located in a low traffic region, it has high levels of asbestos compared to other points. According to the investigations, it was observed that at a distance close to the station, an outdoor workshop which produces construction insulations and flooring is active, which uses large amounts of asbestos to produce its products. Therefore, it is possible that the reason of the high level of asbestos fiber in the station is this issue. By comparing the results of this study with those published from other parts of the world, it is observed that the concentration observed in this study has been higher than the asbestos fiber level across different American and European cities as well as other developed countries (Lim et al. 2004, Lajoie and sociaux 2005, Gualtieri et al. 2009). In recent years, developed countries have decreased their asbestos production or have banned its usage. However, in developing countries such as Iran, many industries use asbestos for producing their products, whereby 2000 tons of chrysotile asbestos is utilized in Iranian industry (Kakooei and Marioryad 2010). As mentioned above, PCM analysis can determine the total asbestos fiber levels in the air, but it is not able to detect the type of asbestos fiber. Therefore, for accurate evaluation of the asbestos level in Tehran's air and detection of the asbestos fiber type, the taken samples were also analyzed by SEM analysis coupled with EDX, with the results provided in Table 1 and Fig. 2. According to the SEM analysis, the asbestos concentration has been over-reported as compared to PCM analysis, which is consistent with the cases reported for the air of other cities in similar studies (Wei et al. 2012). Based on EDX spectra, the chemical composition of each fiber can be identified and then the type of asbestos fiber can be specified. Generally, the spectra with $\mathrm{Fe}, \mathrm{Mg}$, and Si peaks belong to chrysotile (Fig. 3, Part C), the spectra that lack Fe peak belong to termolites (Part B) and those that have Na peak while Mg peak is not clear in them are Crocidolite (Part A). Crocidolite is the most carcinogenic form of asbestos, capable of penetrating the bronchi

Table 1 The level of airborne fibers (fiber/ml) in urban areas of Tehran, Iran (as determined by PCM and SEM analyses)

\begin{tabular}{|c|c|c|c|c|c|c|c|c|c|}
\hline \multirow[t]{2}{*}{ Station } & \multirow[t]{2}{*}{$N$} & \multicolumn{4}{|l|}{ PCM } & \multicolumn{4}{|l|}{ SEM } \\
\hline & & Average & SD & Max & Min & Average & SD & Max & Min \\
\hline $\mathrm{S} 1$ & 8 & 0.0010 & 0.0003 & 0.0014 & 0.0005 & 0.00101 & 0.0005 & 0.00108 & ND \\
\hline $\mathrm{S} 2$ & 8 & 0.0029 & 0.0015 & 0.0054 & 0.0013 & 0.0168 & 0.0089 & 0.0194 & 0.0101 \\
\hline $\mathrm{S} 3$ & 8 & 0.0019 & 0.0007 & 0.0032 & 0.0011 & 0.00124 & 0.00049 & 0.00139 & 0.00098 \\
\hline $\mathrm{S} 4$ & 8 & 0.0016 & 0.0007 & 0.0027 & 0.0009 & 0.00105 & 0.0022 & 0.0011 & ND \\
\hline S5 & 8 & 0.0020 & 0.0007 & 0.0028 & 0.0011 & 0.00821 & 0.0072 & 0.011 & 0.00236 \\
\hline S6 & 8 & 0.0018 & 0.0010 & 0.0035 & 0.0008 & 0.00348 & 0.0033 & 0.00418 & 0.00115 \\
\hline S7 & 8 & 0.0011 & 0.0005 & 0.0018 & 0.0005 & 0.00104 & 0.0046 & 0.00113 & ND \\
\hline S8 & 8 & 0.0025 & 0.0006 & 0.0036 & 0.0018 & 0.0148 & 0.0096 & 0.012 & 0.0158 \\
\hline
\end{tabular}

$N D$ no detection 

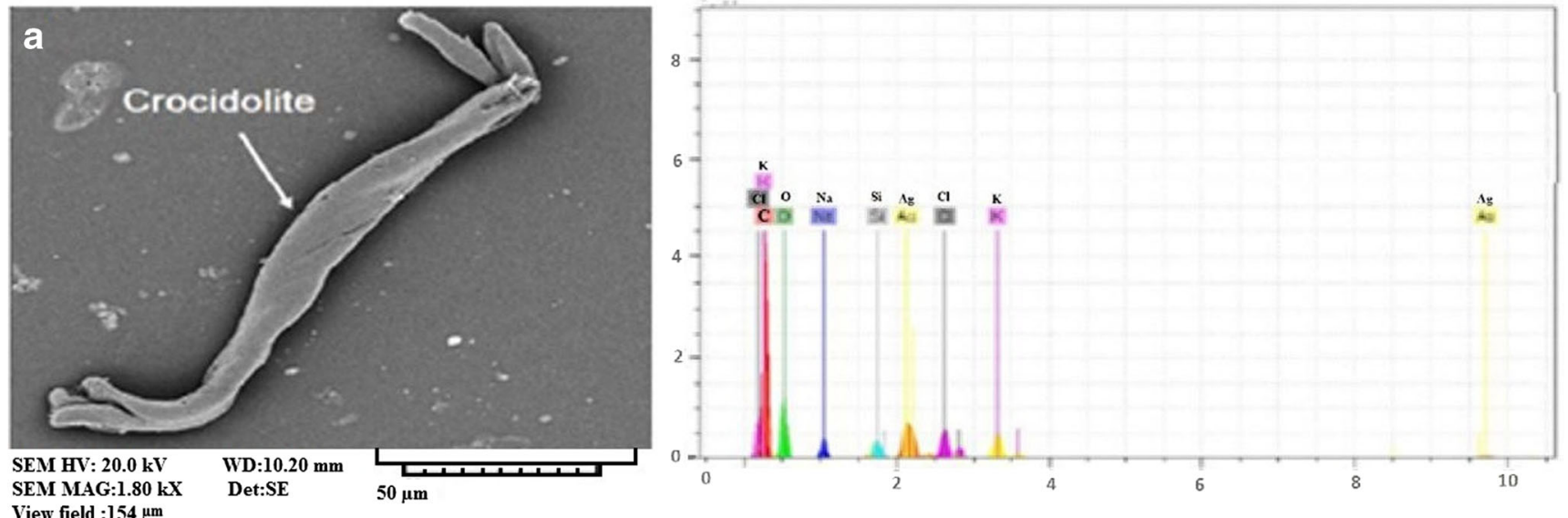

SEM MAG:1.80
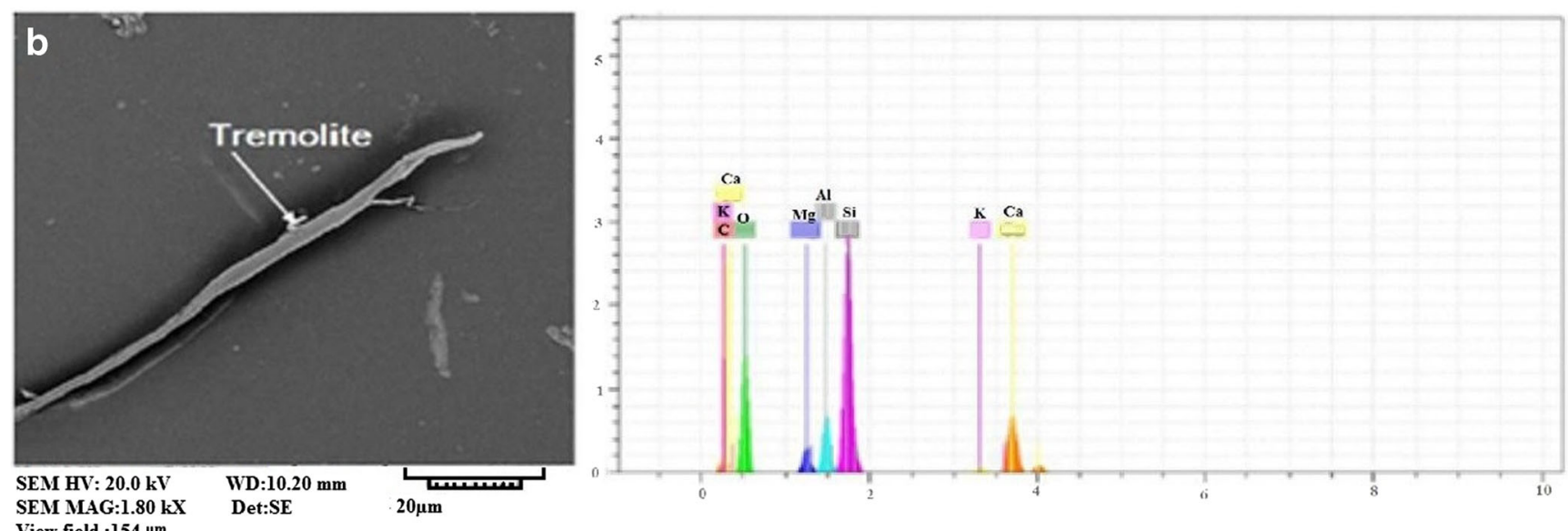

SEM MAG: $1.80 \mathrm{kX}$
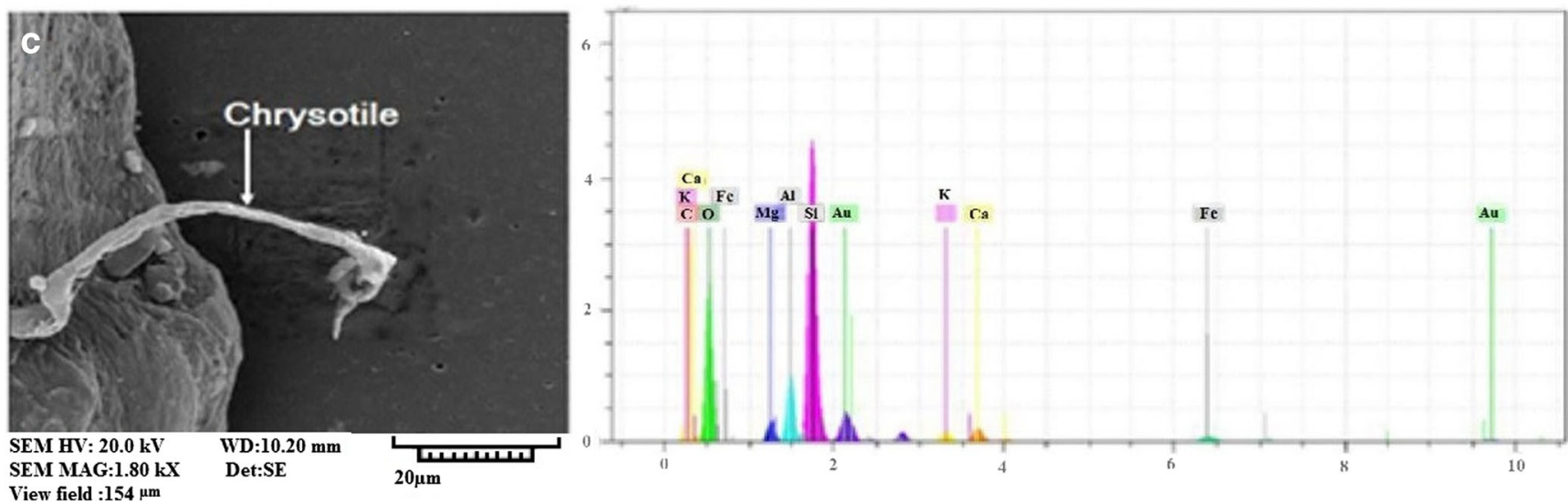

View field : $154 \mu$

Fig. 2 SEM image and EDX spectrum from sample of airborne contamination showing a crocidolite, $\mathbf{b}$ termolite, and $\mathbf{c}$ chrysotile fibers at $\times 1500$ magnification

and then the lungs, ultimately leading to lung cancer (Kakooei and Normohammadi 2014). It has been found that the results of counting by SEM method are around 14-15 times as large as those of PCM method on the same air sample. The reason of this overestimation is that PCM cannot detect fibers for smaller than 0.25 $\mathrm{mm}$, while SEM with its excellent resolution is able to detect fibers with a diameter of less than $0.01 \mathrm{~mm}$ (Marioryad et al. 2011).

\section{Spatial distribution and seasonal variations of the asbestos fiber level}

During the sampling period, the meteorological parameters including the temperature and humidity were also obtained from the closest meteorological stations available in the area, and the relationship between the asbestos concentrations with 
these parameters was evaluated by Pearson analysis, with the results provided in Fig. 3. According to Fig. 3, it is observed that statistically there is no significant correlation between the asbestos concentration and temperature as well as humidity. This means that changes in asbestos fiber concentration are not affected by temperature and humidity differences across any of the collected samples at a $95 \%$ confidence level. These results have been in good accordance with the results reported by other published works (Kakooei et al. 2013).

Figure 4 demonstrates the comparison of seasonal variation in asbestos fiber concentration. As can be observed, the maximum seasonal levels are related to fall, which can be due to the phenomenon of inversion in most days of the fall over the city of Tehran, resulting in higher concentration of air contaminants including asbestos (Malek et al. 2006; Baghani et al. 2018). Although inversion phenomenon also exists during winter, it should be noted that due to the higher precipitation in this season, asbestos fiber levels are lower than in the fall. The minimum asbestos fiber concentration was observed in spring. The possible reason was that during the studied period, the mean precipitations have been higher during spring than in winter. Indeed, precipitation is one of the factors that leads to removal and decreasing of asbestos fiber from the air (Khamutian et al. 2015; Mullaugh et al. 2015). Other researchers have also reported similar findings regarding the level of air pollutants during different seasons of the year (Miri et al. 2016).

Figure 5 demonstrates the distribution of asbestos fibers in the study area; as can be observed, the closer we get to points $\mathrm{S} 2$ and S8, the concentration of asbestos fibers increases due to the source of contamination. However, since there is no source of pollutants at points S1 and S7, the concentration of asbestos fibers decreases as we get closer to these points.

\section{Assessment of potential health effects}

The non-carcinogenic effects of exposure to asbestos are less well understood than the carcinogenic effects. Therefore, the health effects estimated in this study are solely attributed to the carcinogenicity risk resulting from exposure to asbestoscontaminated air. According to carcinogenicity classification, asbestos with the CAS number of 4-21-1332 has been classified as carcinogen Group A - human carcinogen or Group 1carcinogen for humans. In this study, according to IRIS EPA references, risk assessment of asbestos was done based on the data obtained from PCM method. Based on four age groups (including 0-2, 2-6, 6-16, and 16-30-year-old groups), ELCR was determined and reported as sum of the report. Generally, exposure to asbestos fiber in the air depends on the concentration of its fibers in the air and the type of scenario

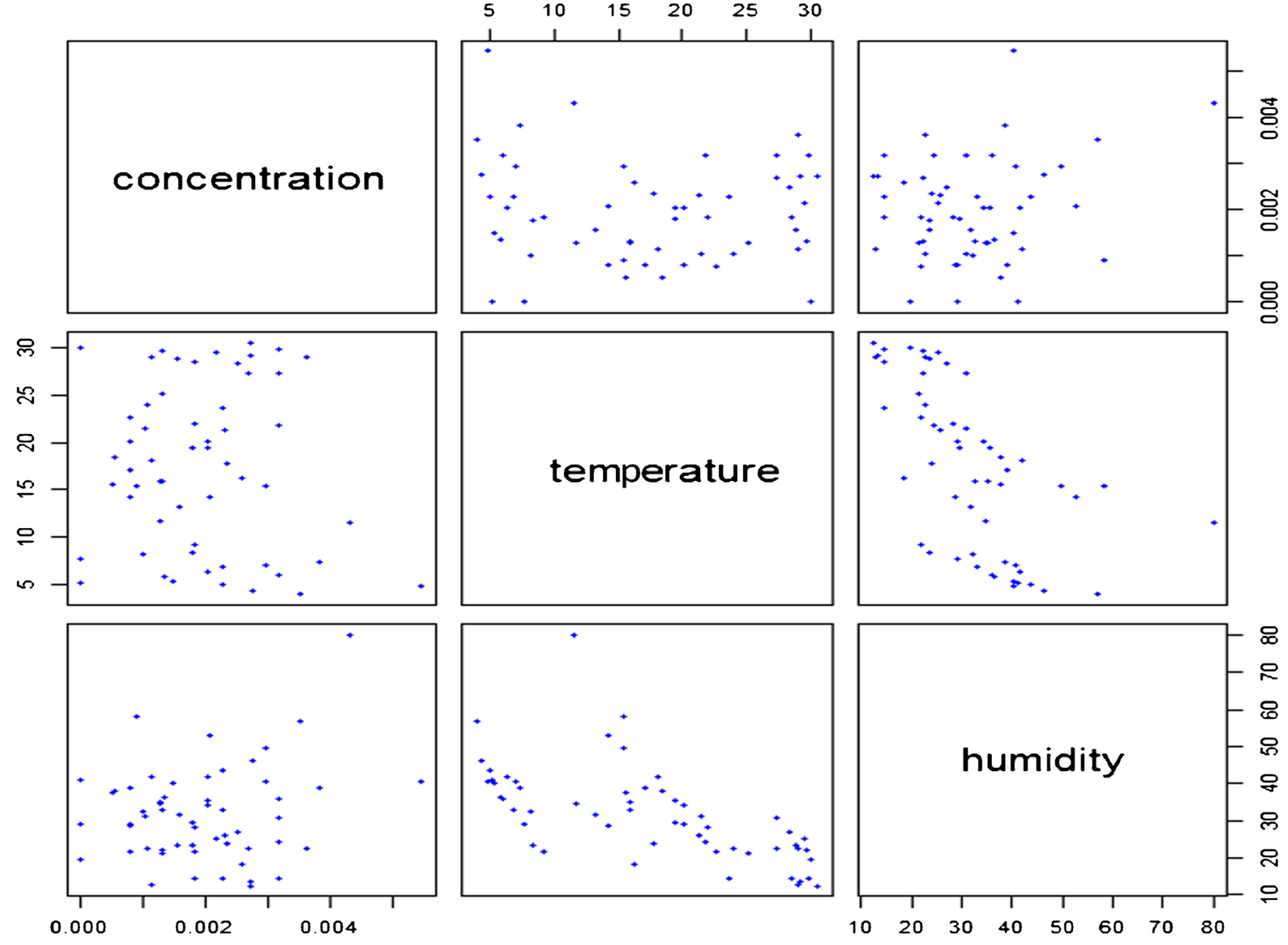

Fig. 3 Spearman correlation between the meteorological parameters and asbestos fiber in samples collected from the ambient air of Tehran 
Fig. 4 Comparison of seasonal variation in asbestos fiber concentration

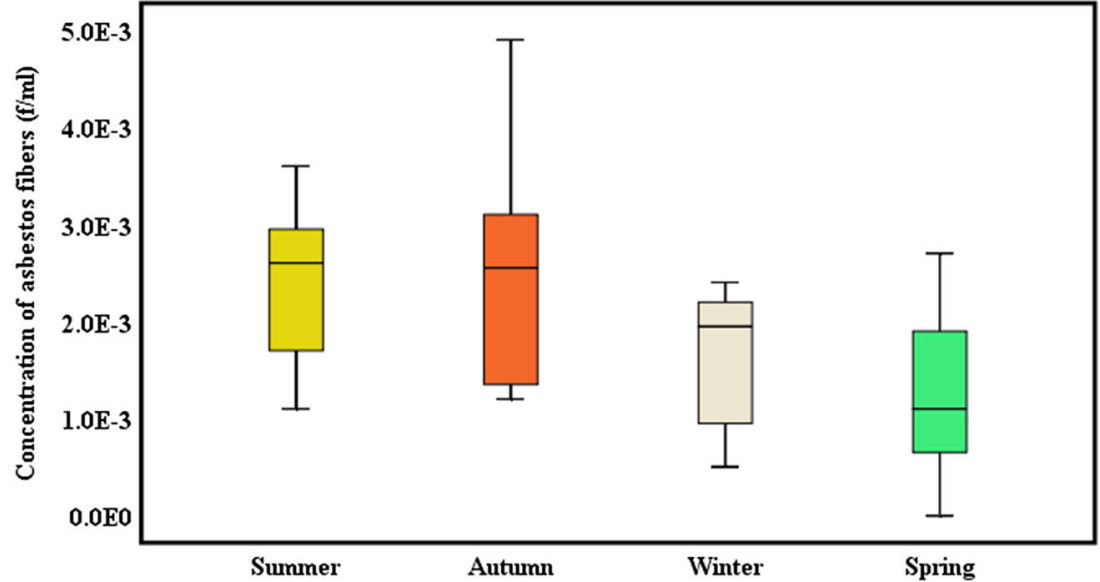

considered for risk assessment. For asbestos risk assessment, there are two scenarios: occupational scenario and public scenario (residential). The difference of these two scenarios lies in the duration of exposure, which is considered $8 \mathrm{~h}$ and $24 \mathrm{~h}$ for the occupational and public environments, respectively. Furthermore, no distinction is made between age groups in the occupational scenario. The exposure concentration (EC) values calculated for the public scenario, age populations, and sample stations are in Table 2. The excess lifetime cancer risk (ELCR) for the public scenario, age populations, and sample stations are calculated and presented in Table 3. According to Table 3, the maximum ELCR value has been related to S2 point with $5.37 * 10^{-04}$, while its lowest value is associated with $\mathrm{S} 1$ point with $5.26^{*} 10^{-05}$. Indeed, these values imply that at S2 point, at which the maximum extent of exposure exists, per each 10,000 individuals, 5.37 persons are at risk of developing cancer due to exposure to asbestos. However, at S1 point in the maximum state per every 10,0000 individuals, 13.42 persons are at risk of cancer. According to the US EPA report, the range of carcinogenicity risk of the pollutants in the air has been presented as $1 * 10^{-6}-1 * 10^{-4}$, which is regarded as a target level. S2 and S8 points exceeded the considered range and have the maximum risk of carcinogenicity.

\section{The limitations of the risk assessment method used in this study}

One of the limitations of this study was that the health risks assessment method used here to examine the carcinogenicity
Fig. 5 Spatial distribution of airborne asbestos fiber (fiber/ml)

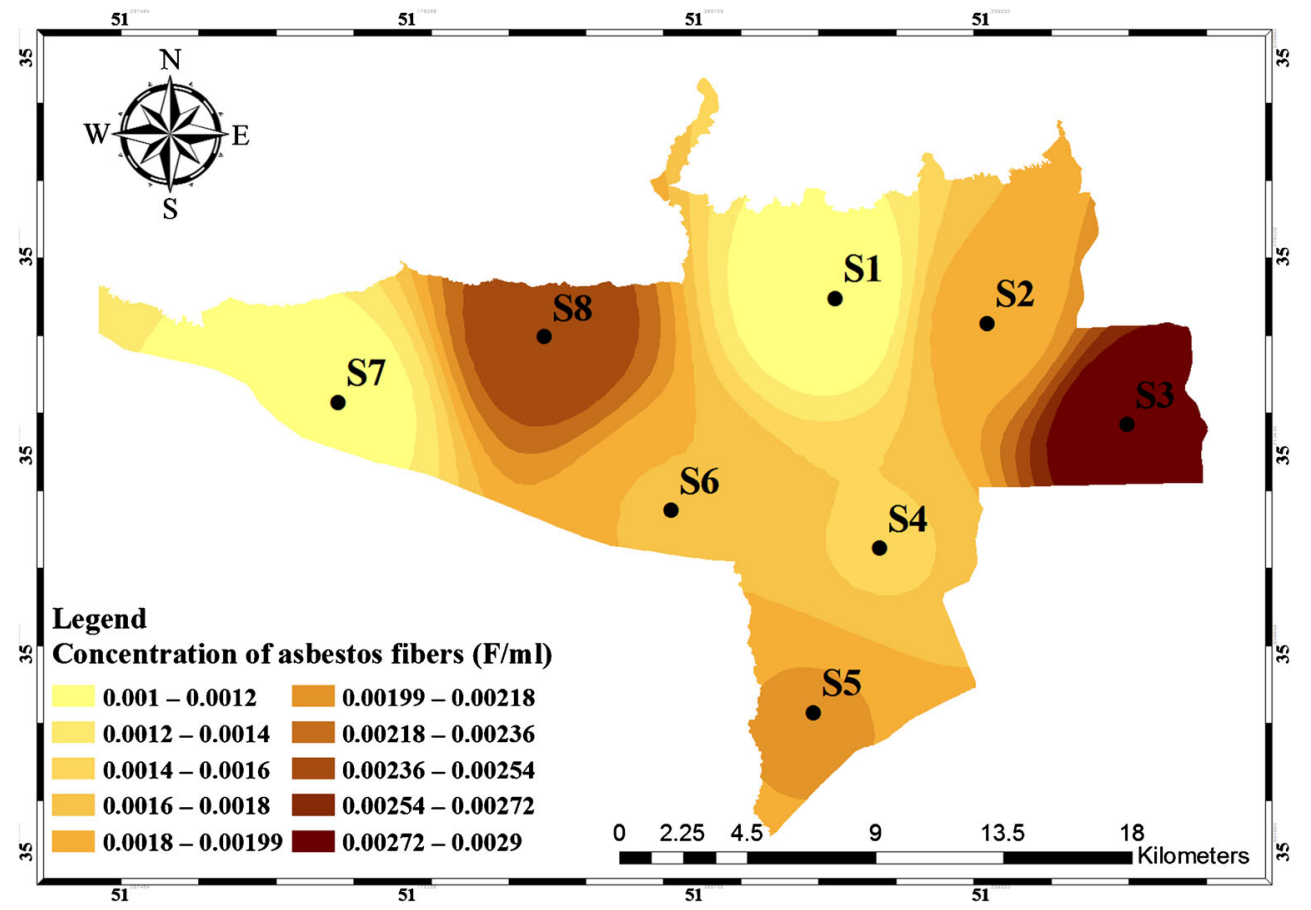


Table 2 The chronic exposure concentrations (ECs) determined for public's exposure, using maximum and minimum fiber counts

\begin{tabular}{|c|c|c|c|c|c|c|c|}
\hline \multicolumn{2}{|l|}{$\mathrm{EC}_{0-2}$} & \multicolumn{2}{|l|}{$\mathrm{EC}_{2-6}$} & \multicolumn{2}{|l|}{$\mathrm{EC}_{6-16}$} & \multicolumn{2}{|l|}{$\mathrm{EC}_{16-30}$} \\
\hline Min & Max & Min & Max & Min & $\operatorname{Max}$ & Min & Max \\
\hline $1.53 \mathrm{E}-05$ & $3.89 \mathrm{E}-05$ & $3.05 \mathrm{E}-05$ & $7.78 \mathrm{E}-05$ & $7.64 \mathrm{E}-05$ & $19.50 \mathrm{E}-05$ & $10.77 \mathrm{E}-05$ & $27.21 \mathrm{E}-05$ \\
\hline $3.76 \mathrm{E}-05$ & $15.56 \mathrm{E}-05$ & $7.52 \mathrm{E}-05$ & $31.10 \mathrm{E}-05$ & $18.8 \mathrm{E}-05$ & $77.81 \mathrm{E}-05$ & $26.31 \mathrm{E}-05$ & $10.95 \mathrm{E}-04$ \\
\hline $3.01 \mathrm{E}-05$ & $9.08 \mathrm{E}-05$ & $6.01 \mathrm{E}-05$ & $18.25 \mathrm{E}-05$ & $15 \mathrm{E}-05$ & $45.40 \mathrm{E}-05$ & $21.12 \mathrm{E}-05$ & $63.60 \mathrm{E}-05$ \\
\hline $2.59 \mathrm{E}-05$ & $7.78 \mathrm{E}-05$ & $5.19 \mathrm{E}-05$ & $15.65 \mathrm{E}-05$ & $13.24 \mathrm{E}-05$ & $38.91 \mathrm{E}-05$ & $18.21 \mathrm{E}-05$ & $54.55 \mathrm{E}-05$ \\
\hline $3.01 \mathrm{E}-05$ & $7.86 \mathrm{E}-05$ & $6.02 \mathrm{E}-05$ & $15.70 \mathrm{E}-05$ & $15.38 \mathrm{E}-05$ & $39.33 \mathrm{E}-05$ & $21.15 \mathrm{E}-05$ & $55.10 \mathrm{E}-05$ \\
\hline $2.31 \mathrm{E}-05$ & $10.06 \mathrm{E}-05$ & $4.63 \mathrm{E}-05$ & $20.11 \mathrm{E}-05$ & $11.60 \mathrm{E}-05$ & $50.33 \mathrm{E}-05$ & $16.20 \mathrm{E}-05$ & $70.41 \mathrm{E}-05$ \\
\hline $1.53 \mathrm{E}-05$ & $5.14 \mathrm{E}-05$ & $3.07 \mathrm{E}-05$ & $10.36 \mathrm{E}-05$ & $7.67 \mathrm{E}-05$ & $25.75 \mathrm{E}-05$ & $10.73 \mathrm{E}-05$ & $36 \mathrm{E}-05$ \\
\hline $5.09 \mathrm{E}-05$ & $10.37 \mathrm{E}-05$ & $10.25 \mathrm{E}-05$ & $20.88 \mathrm{E}-05$ & $25.50 \mathrm{E}-05$ & $51.90 \mathrm{E}-05$ & $35.70 \mathrm{E}-05$ & $72.70 \mathrm{E}-05$ \\
\hline
\end{tabular}

risks for people exposed to asbestos was simple, which develop some ambiguity, and as a result, the obtained findings cannot be considered definite and absolute findings. Indeed, the presented method is based on a conservative approach for risk assessment which tends to overestimate, causing a series of uncertainties for the assessment, as mentioned below. Firstly, the exposure parameters utilized in these risk calculations (hour/day, day/year) were based on the assumption that the residents will stay in the same location (Tehran) for the entire time span. It is also evident to those who have spent a significant amount of time inside their homes, where the asbestos fiber level in the indoor air differs from that outside. Secondly, the asbestos fiber concentration in the air will not remain at a constant level throughout the life span of individuals, and it will change daily and even hourly. Thirdly, the minimum and maximum values of fiber concentration were used in the risk assessment calculations. Therefore, the real risks should be between these two values. Fourthly, the risk assessment calculations were based on PCM results, which are based on the total asbestos concentration, and no distinction has been made between the type of asbestos fiber (Crocidolite, chrysotile). Finally, confounding factors such as smoking habits and a diet of exposed individuals have not been taken into account in the estimates.

\section{Conclusion}

This research has provided information related to the concentration, spatial distribution, seasonal variation, and health risk assessment of airborne asbestos fibers in ambient air of Tehran, Iran. The findings of this study indicated that asbestos fibers are ubiquitous environmental pollutants in this area, which its concentration is higher than the guideline value calculated for lifespan exposure. Our findings suggested that the high levels of airborne asbestos in Tehran's ambient air were primarily due to the city's high traffic load, high industrial asbestos usage, and the climatic and geographical conditions. It was also observed that the mean concentration of asbestos fibers was significantly higher in fall season, compared with other seasons. In spite of

Table 3 The lifetime excess cancer risk (ELCR) calculated for non-occupational exposure, using maximum and minimum fiber counts

\begin{tabular}{|c|c|c|c|c|c|c|c|c|c|c|}
\hline \multirow[t]{2}{*}{ Station } & \multicolumn{2}{|l|}{$\mathrm{ELCR}_{0-2}$} & \multicolumn{2}{|l|}{$\mathrm{ELCR}_{2-6}$} & \multicolumn{2}{|l|}{$\mathrm{ELCR}_{6-16}$} & \multicolumn{2}{|l|}{$\mathrm{ELCR}_{16-30}$} & \multicolumn{2}{|l|}{$\mathrm{ELCR}_{\text {total }}$} \\
\hline & Min & Max & Min & Max & Min & Max & Min & Max & Min & Max \\
\hline $\mathrm{S} 1$ & $3.51 \mathrm{E}-06$ & $8.95 \mathrm{E}-06$ & $7.024 \mathrm{E}-06$ & $1.79 \mathrm{E}-05$ & $1.75 \mathrm{E}-05$ & $4.47 \mathrm{E}-05$ & $2.45 \mathrm{E}-05$ & $6.26 \mathrm{E}-05$ & $5.26 \mathrm{E}-05$ & $13.42 \mathrm{E}-05$ \\
\hline S2 & $8.65 \mathrm{E}-06$ & $3.58 \mathrm{E}-05$ & $1.73 \mathrm{E}-05$ & $7.16 \mathrm{E}-05$ & $4.32 \mathrm{E}-05$ & $17.91 \mathrm{E}-05$ & $6.05 \mathrm{E}-05$ & $25.11 \mathrm{E}-05$ & $12.9696 \mathrm{E}-05$ & $5.3722 \mathrm{E}-04$ \\
\hline S3 & $6.91 \mathrm{E}-06$ & $2.08 \mathrm{E}-05$ & $1.38 \mathrm{E}-05$ & $4.17 \mathrm{E}-05$ & $3.46 \mathrm{E}-05$ & $10.44 \mathrm{E}-05$ & $4.84 \mathrm{E}-05$ & $14.62 \mathrm{E}-05$ & $10.37 \mathrm{E}-05$ & $31.33 \mathrm{E}-05$ \\
\hline S4 & $5.96 \mathrm{E}-06$ & $1.79 \mathrm{E}-05$ & $1.19 \mathrm{E}-05$ & $3.58 \mathrm{E}-05$ & $2.98 \mathrm{E}-05$ & $8.95 \mathrm{E}-05$ & $4.17 \mathrm{E}-05$ & $12.53 \mathrm{E}-05$ & $8.95 \mathrm{E}-05$ & $26.86 \mathrm{E}-05$ \\
\hline S5 & $6.92 \mathrm{E}-06$ & $1.80 \mathrm{E}-05$ & $1.38 \mathrm{E}-05$ & $3.61 \mathrm{E}-05$ & $3.46 \mathrm{E}-05$ & $9.047 \mathrm{E}-05$ & $4.84 \mathrm{E}-05$ & $12.67 \mathrm{E}-05$ & $10.38 \mathrm{E}-05$ & $27.11 \mathrm{E}-05$ \\
\hline S6 & $5.32 \mathrm{E}-06$ & $2.314 \mathrm{E}-05$ & $1.064 \mathrm{E}-05$ & $4.62 \mathrm{E}-05$ & $2.66 \mathrm{E}-05$ & $11.56 \mathrm{E}-05$ & $3.72 \mathrm{E}-05$ & $16.20 \mathrm{E}-05$ & $7.98 \mathrm{E}-05$ & $34.70 \mathrm{E}-05$ \\
\hline S7 & $3.52 \mathrm{E}-06$ & $1.18 \mathrm{E}-05$ & $7.052 \mathrm{E}-06$ & $2.36 \mathrm{E}-05$ & $1.76 \mathrm{E}-05$ & $5.91 \mathrm{E}-05$ & $2.46 \mathrm{E}-05$ & $8.28 \mathrm{E}-05$ & $5.28 \mathrm{E}-05$ & $17.70 \mathrm{E}-05$ \\
\hline S8 & $1.17 \mathrm{E}-05$ & $2.38 \mathrm{E}-05$ & $2.34 \mathrm{E}-05$ & $4.77 \mathrm{E}-05$ & $5.85 \mathrm{E}-05$ & $11.93 \mathrm{E}-05$ & $8.20 \mathrm{E}-05$ & $16.71 \mathrm{E}-05$ & $17.57 \mathrm{E}-05$ & $3.58 \mathrm{E}-04$ \\
\hline
\end{tabular}

This difference could be due to the presence of inversions in cold seasons in Tehran 
the human health effects, it was found that the ELCR calculated for all the sampling areas is between $5.26 \times 10^{-5}$ and $5.37 \times$ $10^{-04}$. Based on the used standards, these levels are categorized rather to moderate levels. In general, these findings highlight the importance of asbestos fiber control strategies in megacities with high traffic rate and industrial activities. More comprehensive research is urgently needed to identify and monitor the sources of asbestos fiber emissions in order to reduce their levels in the future. For this purpose, the things that can be done include bans on the application of asbestos, standardization vehicle and fuels, development of public transportation, and industrial releasing control.

Funding For this study, the authors received financial and technical support (Grant No. 96-02-212-31563) from Iran University of Medical Sciences.

\section{Declarations}

Conflict of interest The authors declare that they have no competing interests.

\section{References}

Abbasi F, Pasalari H, Delgado-Saborit JM, Rafiee A, Abbasi A, Hoseini M (2020) Characterization and risk assessment of BTEX in ambient air of a Middle Eastern City. Process Saf Environ Prot 139:98-105

Baghani AN, Rostami R, Arfaeinia H, Hazrati S, Fazlzadeh M, Delikhoon M (2018) BTEX in indoor air of beauty salons: risk assessment, levels and factors influencing their concentrations. Ecotoxicol Environ Saf 159:102-108

Bayat R, Ashrafi K, Shafiepour Motlagh M, Hassanvand MS, Daroudi R, Fink G, Künzli N (2019) Health impact and related cost of ambient air pollution in Tehran. Environ Res 176:108547

Cancer, I. A. f. R. o (1977) IARC monographs on the evaluation of carcinogenic risk of chemicals to man, vol 14. Asbestos

Commins B (1985) The significance of asbestos and other mineral fibres in environmental ambient air. Commins Associates, Kenilworth

Environmental Protection Agency U (1986) Guidelines for carcinogen risk assessment. Federal Register 51:33-1034

Faigout D (1985) Environmental release of asbestos from commercial product shaping. Project Summary. Environmental Protection Agency, Research and Development, Research Laboratory Cincinnati, OH, 45268

Faridi S, Niazi S, Yousefian F, Azimi F, Pasalari H, Momeniha F, Mokammel A, Gholampour A, Hassanvand MS, Naddafi K (2019) Spatial homogeneity and heterogeneity of ambient air pollutants in Tehran. Sci Total Environ 697:134123

Gualtieri AF, Mangano D, Gualtieri ML, Ricchi A, Foresti E, Lesci G, Roveri N, Mariotti M, Pecchini G (2009) Ambient monitoring of asbestos in selected Italian living areas. J Environ Manag 90(11): $3540-3552$

Jiang GC et al (2008) A study of airborne chrysotile concentrations associated with handling, unpacking, and repacking boxes of automobile clutch discs. Regul Toxicol Pharmacol 51(1):87-97
Kakooei H, Marioryad H (2010) Evaluation of exposure to the airborne asbestos in an automobile brake and clutch manufacturing industry in Iran. Regul Toxicol Pharmacol 56(2):143-147

Kakooei H, Normohammadi M (2014) Asbestos exposure among construction workers during demolition of old houses in Tehran, Iran. Ind Health 52(1):71-77

Kakooei $\mathrm{H}$ et al (2007) Asbestos exposure during routine brake lining manufacture. Ind Health 45(6):787-792

Kakooei $\mathrm{H}$ et al (2009) Assessment of airborne asbestos fiber concentrations in urban area of Tehran, Iran. Air Qual Atmos Health 2(1):39

Kakooei H, Meshkani M, Azam K (2013) Ambient monitoring of airborne asbestos in non-occupational environments in Tehran, Iran. Atmos Environ 81:671-675

Khadem M, Somea MS, Hassankhani H, Heravizadeh OR (2018) Joint Iranian-Russian studies of airborne asbestos concentrations in Tehran, Iran, in 2017. Atmos Environ 186:9-17

Khamutian $\mathrm{R}$ et al (2015) The association between air pollution and weather conditions with increase in the number of admissions of asthmatic patients in emergency wards: a case study in Kermanshah. Med J Islam Repub Iran 29:229

Lajoie P, Q. M. d. 1. s. e. d. s. sociaux (2005) Asbestos fibres in indoor and outdoor air: the situation in Quebec. Institut national de santé publique du Québec, Montréal

Lim H-S et al (2004) Airborne asbestos and non-asbestos fiber concentrations in non-occupational environments in Korea. Ind Health 42(2): 171-178

Malek E, Davis T, Martin RS, Silva PJ (2006) Meteorological and environmental aspects of one of the worst national air pollution episodes (January, 2004) in Logan, Cache Valley, Utah, USA. Atmos Res 79(2):108-122

Marioryad H, Kakooei H, Shahtaheri SJ, Yunesian M, Azam K (2011) Assessment of airborne asbestos exposure at an asbestos cement sheet and pipe factory in Iran. Regul Toxicol Pharmacol 60(2): 200-205

Miri M, Rostami Aghdam Shendi M, Ghaffari HR, Ebrahimi Aval H, Ahmadi E, Taban E, Gholizadeh A, Yazdani Aval M, Mohammadi A, Azari A (2016) Investigation of outdoor BTEX: concentration, variations, sources, spatial distribution, and risk assessment. Chemosphere 163:601-609

Mokhtari M, Jafari N, Mohammadi A, Hajizadeh Y, Ghanbari R, Nemati S, Abdolahnejad A (2019) Temporal and spatial trends of airborne asbestos fiber concentrations in the urban areas of Yazd, Iran. Int J Environ Sci Technol 16(6):2657-2666

Moteallemi A, Minaei M, Tahmasbizadeh M, Fadaei S, Masroor K, Fanaei F (2020) Monitoring of airborne asbestos fibers in an urban ambient air of Mashhad City, Iran: levels, spatial distribution and seasonal variations. J Environ Health Sci Eng 18(2):1239-1246

Mullaugh KM, Hamilton JM, Avery GB, Felix JD, Mead RN, Willey JD, Kieber RJ (2015) Temporal and spatial variability of trace volatile organic compounds in rainwater. Chemosphere 134:203-209

Naghavi M (2005) Iranian annual of national death registration report. Iran Ministry of Health and Medical Education, Tehran

Napolitano A, Pellegrini L, Dey A, Larson D, Tanji M, Flores EG, Kendrick B, Lapid D, Powers A, Kanodia S, Pastorino S, Pass HI, Dixit V, Yang H, Carbone M (2016) Minimal asbestos exposure in germline BAP1 heterozygous mice is associated with deregulated inflammatory response and increased risk of mesothelioma. Oncogene 35(15):1996-2002

Pastuszka JS (2009) Emission of airborne fibers from mechanically impacted asbestos-cement sheets and concentration of fibrous aerosol in the home environment in Upper Silesia, Poland. J Hazard Mater 162(2-3):1171-1177 
Pawełczyk A, Božek F (2015) Health risk associated with airborne asbestos. Environ Monit Assess 187(7):428

Sullivan JB, Krieger GR (2001) Clinical environmental health and toxic exposures. Lippincott Williams \& Wilkins, Philadelphia

Walton W (1982) The nature, hazards and assessment of occupational exposure to airborne asbestos dust: a review. Ann Occup Hyg 25(2): $117-119$
Wei B et al (2012) Airborne crocidolite asbestos fibers in indoor and outdoor air in a rural area, China

WHO (2000a) Asbestos. Air quality guidelines, 2nd edn. WHO Regional Office for Europe, Copenhagen (Chapter 6.2)

WHO ( 2000b) Air quality guidelines for Europe, 2nd edn. WHO Regional Publications European Series, No. 91 